\title{
Fitted Copula Statistical Models for Four African and Four Major Stock Markets
}

\author{
Ngozi Fidelia Adum ${ }^{1, *}$, Happiness Onyebuchi Obiora-Ilouno ${ }^{2}$ and \\ Francis Chukwuemeka Eze ${ }^{3}$
}

${ }^{1}$ Department of Statistics, Faculty of Physical Sciences, Nnamdi Azikiwe University, Awka, Nigeria e-mail: fideladum@gmail.com

${ }^{2}$ Department of Statistics, Faculty of Physical Sciences, Nnamdi Azikiwe University, Awka, Nigeria e-mail: obiorailounoho@yahoo.com

${ }^{3}$ Department of Statistics, Faculty of Physical Sciences, Nnamdi Azikiwe University, Awka, Nigeria e-mail: fc.eze@unizik.edu.ng

\begin{abstract}
The application of copula has become popular in recent years. The use of correlation as a dependence measure has several pitfalls and hence the application of regression prediction model using this correlation may not be an appropriate method. In financial markets, there is often a non-linear dependence between returns. Thus, alternative methods for capturing co-dependency should be considered, such as copula based ones. This paper studies the dependence structure between the four largest African stock markets in terms of market capitalization and other developed stock markets over the period 2003 to 2018 using copula models. The value at risk was used to determine the risk associated with the stock. The ten copula models were fitted to the log returns calculated from the data, two countries at a time of the twenty-eight pairs and examined. The Gumbel copula gives the best fit in terms of log-likelihood values, value of the Akaike information criterion, value of the Bayesian information criterion, value of the consistent Akaike information criterion, value of the corrected Akaike information criterion, value of the Hannan Quinn criterion and p-value of the information matrix equality of White. Estimates of value at risk with probability $\mathrm{p}$ for daily returns were computed using the best fitted copula model, from these value at risk, it is seen that SA/FTSE100 have the least risk while EGY/KEN has the highest risk. Prediction is given in terms of correlation and value at risk.
\end{abstract}

Received: May 11, 2021; Accepted: June 18, 2021

2010 Mathematics Subject Classification: 62-XX.

Keywords and phrases: copula, Akaike, Bayesian, Hannan-Quinn.

*Corresponding author

Copyright () 2021 the Authors 


\section{Introduction}

The formation of regional bodies like African Union (AU), Economic Community of West African States (ECOWAS) does not only have political implications to the countries in question, but economic ones as well. Trade amongst the various countries in the region can lead to mutual benefits or losses. It is imperative to assess the extent to which dependence amongst these countries influence their economies. According to Bekaert and Harvey [6], though the joint distribution of multivariate variables are usually assumed to follow the normal distribution, economic variable like the stock market index do not follow the normal distribution since they tend to be skewed, peaked and have extreme values.

Research in emerging stock markets has suggested a number of empirical characteristics that international investors should be aware of. In particular, there is a growing body of evidence that emerging market securities (such as African stock markets) tend to offer larger returns with higher volatility compared to developed stock markets (e.g. Harvey [29], Bekaert et al. [8], Bekaert and Harvey [7]). In addition, they show greater evidence of predictability (e.g. Harvey [29], Claessens and Gooptu [14]) and lower correlation with developed stock market securities implying significant risk diversification opportunities for international portfolios (e.g. Bailey and Stulz [5], Divecha et al. [19], Harvey [29] and Errunza and Hogan [21]). Although it is also argued that the behavior of emerging markets is affected to a greater extent by local political, economic and social events rather than global events (e.g. Aggarwal et al. [1], Bekaert and Harvey [7] and Susmel and Thompson [45]), more recent evidence has suggested that the diversification benefits of these markets have started to diminish because of changes in investment barriers for international investors (Errunza et al. [22], Bekaert and Harvey [7]).

Melo Mendes [46] studied emerging stock markets of Brazil and Argentina using time varying copula models. They concluded that Student's t copula gives the best fit.

Ausin and Lopes [4] modeled the dependence between Dow Jones Industrial Average and DAX indices using a number of copula class of models. They observed that these stock indices are perfectly described by copula models.

Nelsen [39] explains copula as a function which joins or copules a multivariate distribution function to its one-dimensional marginal distribution function. Indeed, copulas have been described as the "fundamental building blocks for studying multivariate distribution". 
Frees and Valdez [25] in their work, noted that the main attraction of a copula approach is that it enables us model the dependence structure of a multivariate distribution separately from the marginal distribution functions of the individual random variables. This ability to separate the dependence structure from the marginals makes copula much greater modeling flexible tool than is possible with traditional approaches to multivariate problems.

Soytas and Sari [44] analyzed the relationship between energy consumption in industrial and manufacturing sector using multivariate model by incorporating capital and labour in production function. Their results indicated co-integration between the variables for long run relationship. The results of vector error correction (VECM) model reveal that there is unidirectional causality running from energy consumption to manufacturing GDP.

Chukwudum [13] analyzed a homogenous portfolio consisting of the aggregate bivariate losses from the Nigerian insurance using the Generalized Pareto distribution (GPD) and the copula technique. It was observed that the correlation coefficient vary and is generally weak. With the aid of the Archimedean copula, the analysis makes use of the data pair exhibiting the highest correlation to draw particular attention to the importance of taken into account the extremely dependence structure when quantifying the risk capital, allocating risk and when estimating the net reinsurance premium under different reinsurance strategies.

Chang [11] simultaneously investigate the dynamic process of crude oil spot and futures returns and the time-varying and asymmetric dependence between spot and futures returns. Using the Gumbel and Clayton copulas, the time-varying and asymmetric dependence was captured. It was found that jumping behavior is an important process for each market. Spot and futures returns do not have the same jump process and the tail dependence between spot and futures markets is time-varying and asymmetric with the magnitude of upper tail dependence being slightly weaker than that of lower tail dependence.

Chen et al. [12] studied the dependence structure (copula) of multivariate financial time series of U.S. equity returns and exchange rates, considering collections of up to 30 assets simultaneously using Student's t copula and normal copula. Mixed evidence was found against the more flexible Student's t copula; it appears adequate for even large collections of equity returns, but is still rejected for most exchange rate returns though it does provide a better fit than the normal copula. 
Zeevi and Mashal [37] investigated the potential for extreme co-movements between financial assets and its dependence structure. Using likelihood ratio-based method, the Student's t and Guassian copula they show that the presence of extreme co-movements is statistically significant in three asset markets (equities, currencies and commodities), as well as across international (G5) equity markets. The t-dependence structure is well suited for this objective in so far as it provides a natural "first step" generalization of the correlation-based Guassian dependence structure.

Patton [40] studied the time varying conditional joint distribution of the daily Deutsche mark-U.S. dollar and Yen-U.S. dollar exchange rates, over the period from January 1991 to December 2001 using standard AR-TGARCH models. These were employed for the marginal distributions of each exchange rate, and two different copulas were estimated: the bivariate normal distribution, and the 'symmetrised Joe-Clayton' copula. Dependence was greater during appreciations of the U.S. dollar than during depreciations of the U.S. dollar.

Sadegh et al. [41] presented the Multivariate Copula Analysis Toolbox (MvCAT) which comprises different copula to model parameter uncertainty of assessment using joint precipitation-soil moisture anomalies in Del Norte county, California and flood peak and volume frequency analysis in the Saguenay River in Quebec, Canada. It shows that length of record significantly affects the uncertainty of results; MvCAT offers uncertainty bounds for the copula probability isolines. This information is particularly useful in multivariate frequency analysis studies.

Fontaine et al. [24] analysed the censored cost-effectiveness using a copula-based modeling of the joint density and an estimation method of the costs, and quality adjusted life years (QALY) in a cost-effectiveness analysis in case of censoring. They concluded that for the cost-effectiveness such technique without any linearity assumption is a progress since it does not need the specification of a global linear regression model. Hence, the estimation of the marginal distributions for each therapeutic arm, the concordance measures between these populations and the right copulas families is now sufficient to process the whole Cost Effectiveness Analysis.

Kumar and Shoukri [34] studied the application to an aortic regurgitation using copula based prediction models. They showed that copula-based prediction modeling is demonstrated to be an appropriate alternative to the conventional correlation-based prediction modeling since the correlation-based prediction models are not appropriate to model the dependence in populations with asymmetrical tails. They validated their proposed copula-based prediction model using the independent bootstrap samples. 
Lien et al. [35] carried out a study investigating the co-movement and tail dependence between Chinese Yuan and New Taiwan Dollar non-delivery forward (NDF) rates against the U.S. dollar. The copula modeling approach to capture dynamics of correction and tail dependence between two NDF rates was used. It is shown that the interdependence between two NDF rates strengthens as time elapses. In particular, the degree of correlation surges sharply after April 9, 2008 while the degree of tail dependence increases significantly after February 10, 2009. Each time point of change is shown to be close to economic and political events that are supposed to have large impact on the relationship between Chinese Yuan and New Taiwan dollar.

Diawara [18] carried out a study using copula densities to model class conditional distribution of pattern recognition with bayes decision rule. This was because these types of densities are useful when the marginal densities of a pattern vector are not normally distributed. Those models are also useful for a mixed pattern vectors. A simulation to compare the performance of the copula based classifier with classical normal distribution based model and the independent assumption based model was also carried out.

$\mathrm{Hu}$ [30] studied dependence structures in Chinese and U.S. Financial Markets with other developed markets (Germany, France, Britain, and Japan) using time varying conditional copula (Normal and Joe Clayton copulas). The study was shown that Chinese is least affected by co-movement in the markets while western markets experience downturns during the ongoing global financial crisis. He suggested investors to increase weights on financial assets from Chinese financial markets in their portfolio for diversification purpose.

\section{Methodology}

\subsection{Source of data}

The data used for this thesis are secondary data. The data are daily stock indices from the $29^{\text {th }}$ April 2003 to the $5^{\text {th }}$ of February 2018 of four African countries and four developed countries: Nigeria (NSE), Kenya (NSE20), Egypt (EGX30), South Africa (JSE40), UK (FTSE), US (SP500), Germany (DAX) and Canada (CAC40). The data were obtained from the database DataStream. Following the tradition, logarithmic returns were calculated as

$$
R_{i, t}=\log \left(\frac{P_{i, t}}{P_{i, t-1}}\right),
$$




$$
C(u, v)= \begin{cases}u^{1-\alpha} v, & \text { if } u^{\alpha} \geq v^{\beta} \\ u v^{1-\beta}, & \text { if } u^{\alpha}<v^{\beta}\end{cases}
$$

where $R_{i, t}$ is the return on the index $i$ for period $t, P_{i, t}$ is the closing price of the index at the end of period $t$ and $P_{i, t-1}$ is the price of the index at the end of the period $t-1$.

\subsection{Copula}

A $p$-dimensional copula is a function $C:[0,1]^{p} \rightarrow[0,1]$ that satisfies

(i) $C\left(u_{1}, \ldots, u_{i-1}, 0, u_{i+1}, \ldots, u_{p}\right)=0$ for all $1 \leq i \leq p$;

(ii) $C(1, \ldots, 1, u, 1, \ldots, 1)=u$ for $u$ in each of the $p$ arguments;

(iii) for $a_{i} \leq b_{i}, i=1, \ldots, p$,

$$
\sum_{i 1=1}^{2} \ldots \sum_{i p=1}^{2}(-1)^{i 1+\cdots+i p} C\left(u_{1, i 1}, \ldots, u_{p, i p}\right) \geq 0
$$

where $u_{j, 1}=a_{j}$ and $u_{j, 2}=b_{j}$ for $j=1, \ldots, p$.

A copula can be used to specify a multivariate distribution and every multivariate distribution gives a copula. If $F_{i}, i=1, \ldots, p$ are one-dimensional cumulative distribution functions, then

$$
F\left(x_{1}, \ldots, x_{p}\right)=C\left(F_{1}\left(x_{1}\right), \ldots, F_{p}\left(x_{p}\right)\right)
$$

is a $p$-dimensional cumulative distribution function. If $F$ is a $p$-dimensional cumulative distribution function then

$$
C\left(u_{1}, \ldots, u_{p}\right)=F\left(F_{1}^{-1}\left(u_{1}\right), \ldots ., F_{p}^{-1}\left(u_{p}\right)\right)
$$

is a $p$-dimensional copula, where $0 \leq u_{1} \leq 1, \quad i=1, \ldots, p \quad$ and $F_{i}(x)=F(\infty, \ldots, \infty, x, \infty, \ldots, \infty), i=1, \ldots, p$ with $x$ being the $i$ th argument. If

$$
C\left(u_{1}, \ldots, u_{p}\right)=u_{1} \ldots u_{p} .
$$

Then the distribution is said to exhibit independence. If 


$$
C\left(u_{1}, \ldots, u_{p}\right)=\min \left(u_{1}, \ldots, u_{p}\right)
$$

Then the distribution is said to exhibit complete dependence.

Restricting attention to the bivariate case for the sake of simplicity, the copula approach to dependence modeling is rooted in a representation theorem due to Sklar [43] as earlier mentioned. The Sklar theorem states that the joint cumulative distribution function (cdf) $H(x, y)$ of any pair $(X, Y)$ of continuous random variables may be written in the form

$$
H(x, y)=C\{F(x), G(y)\}, \quad x, y \in R
$$

where $F(x)$ and $G(y)=$ marginal distributions; $C:[0,1]^{2} \rightarrow[0,1]=$ copula. While Sklar [43] showed that $C, F$ and $G$ are uniquely determined when $H$ is known, a valid model for $(X, Y)$ arises from equation 1 whenever the three are chosen from given parametric families of distribution, viz.:

$$
F \in\left(F_{\delta}\right), G \in\left(G_{\eta}\right), C \in\left(C_{\theta}\right) .
$$

Thus, for example, $F$ might be normal with (bivariate) parameter $\delta=\left(\mu, \sigma^{2}\right)$; $G$ might be gamma with parameter $\eta=(\alpha, \lambda)$; and $C$ might be taking from the Farlie-GumbelMorgenstern family of copulas, defined $\theta \in[-1,1]$ by

$$
C_{\theta}(u, v)=u v+\theta u v(1-u)(1-v), u, v \in[0,1] .
$$

\subsection{Copula model specifications}

Let $U$ and $V$ be uniform $[0,1]$ random variables. A copula denoted by say $C(u, v)$ is a joint cumulative distribution function of $U$ and $V$. A copula density denoted by say $c(u, v)$ is the joint probability density function of $U$ and $V$. Ten different models for copula were considered:

\subsubsection{The Guassian copula}

The Guassian copula defined by

$$
C(u, v)=\Phi_{p}\left(\Phi^{-1}(u), \Phi^{-1}(v)\right),
$$

where $\Phi$ denotes the cumulative distribution function of a standard normal random 
variable and $\Phi_{p}$ denotes the joint cumulative distribution function of a bivariate normal random vector with zero means, unit variances and correlation $\rho$. The corresponding copula density is

$$
\begin{aligned}
c(u, v)= & \frac{\phi\left(\Phi^{-1}(u)\right) \phi\left(\Phi^{-1}(v)\right)}{2 \pi \sqrt{1-\rho^{2}}} \\
& \cdot \exp \left\{-\frac{\left[\Phi^{-1}(u)\right]^{2}+\left[\Phi^{-1}(v)\right]^{2}-2 \rho \Phi^{-1}(u) \Phi^{-1}(u)}{2\left(1-\rho^{2}\right)}\right\},
\end{aligned}
$$

where $\phi$ denotes the probability density function of a standard normal random variable. Independence of $U$ and $V$ corresponds to $\rho=0$. Complete dependence of $U$ and $V$ corresponds to $\rho=1$.

\subsubsection{The t copula}

The $t$ copula defined by

$$
C(u, v)=\mathrm{T}_{\rho, v}\left(\mathrm{~T}_{v}^{-1}(u), \mathrm{T}_{v}^{-1}(v)\right),
$$

where $\mathrm{T}_{v}$ denotes the cumulative distribution function of a Student's $t$ random variable with degrees of freedom $v$ and $T_{p, v}$ denotes the joint cumulative distribution function of a bivariate $t$ random vector with zero means, correlation $\rho$ and degrees of freedom $v$. The corresponding copula density is

$$
\begin{aligned}
c(u, v)= & \frac{t_{v}\left(\mathrm{~T}_{v}^{-1}(u)\right) t_{v}\left(\mathrm{~T}_{v}^{-1}(v)\right)}{2 \pi \sqrt{1-\rho^{2}}} \\
& \cdot\left\{1+\frac{\left[\mathrm{T}_{v}^{-1}(u)\right]^{2}+\left[\mathrm{T}_{v}^{-1}(v)\right]^{2}-2 p \mathrm{~T}_{v}^{-1}(u) \mathrm{T}_{v}{ }^{-1}(u)}{v\left(1-\rho^{2}\right)}\right\}^{-(v+1) / 2},
\end{aligned}
$$

where $t_{v}$ denotes the probability density function of a Student's $t$ random variable with $v$ degrees of freedom.

\subsubsection{The Ali-Mikhail-Haq copula}

The Ali-Mikhail-Haq copula due to Ali et al. [3] defined by 


$$
C(u, v)=(1-\alpha)\left[\left(\frac{1-\alpha}{u}+\alpha\right)\left(\frac{1-\alpha}{v}+\alpha\right)-\alpha\right]^{-1}
$$

For $-1 \leq \alpha \leq 1$, the corresponding copula density is

$$
c(u, v)=\frac{1-2 \theta+\theta u v+\theta^{2} u v-\theta^{2} u+\theta u+\theta v-\theta^{2} v+\theta^{2}}{(1-\theta+\theta u+\theta v-\theta u v)^{3}}
$$

Independence of $U$ and $V$ corresponds to $\alpha=0$.

\subsubsection{The Clayton copula}

The Clayton copula due to Clayton [15] defined by

$$
C(u, v)=\left[u^{-\alpha}+v^{-\alpha}-1\right]^{-1 / \alpha}
$$

For $-\infty<\alpha<\infty$, the corresponding copula density is

$$
c(u, v)=(1+\alpha)(u v)^{-\alpha-1}\left[u^{-\alpha}+v^{-\alpha}-1\right]^{-1 / \alpha-2} .
$$

Independence of $U$ and $V$ corresponds to $\alpha=0$. Complete dependence of $U$ and $V$ correspond to $\alpha=\infty$.

\subsubsection{The Farlie-Gumbel-Morgenstern copula}

The Farlie-Gumbel-Morgenstern copula (Morgenstern [38]) defined by

$$
C(u, v)=u v[1+\theta(1-u)(1-v)] .
$$

For $-1 \leq \theta \leq 1$, the corresponding copula density is

$$
c(u, v)=1+\theta(1-2 u-2 v+4 u v) .
$$

Independence of $U$ and $V$ corresponds to $\theta=0$.

\subsubsection{The Cuadras-Augé copula}

The Cuadras-Augé copula due to Cuadras and Augé [16] defined by

$$
C(u, v)=[\min (u, v)]^{\theta}(u v)^{1-\theta}
$$

For $0 \leq \theta \leq 1$, the corresponding copula density is 


$$
c(u, v)= \begin{cases}(1-\theta) v^{-\theta}, & u \leq v, \\ (1-\theta) u^{-\theta}, & u>v .\end{cases}
$$

Independence of $U$ and $V$ corresponds to $\theta=0$. Complete dependence of $U$ and $V$ corresponds to $\theta=1$.

\subsubsection{The Marshall-Olkin copula}

The Marshall-Olkin copula due to Marshall and Olkin [36] defined by

$$
C(u, v)= \begin{cases}u^{1-\alpha} v, & \text { if } u^{\alpha} \geq v^{\beta}, \\ u v^{1-\beta}, & \text { if } u^{\alpha}<v^{\beta} .\end{cases}
$$

For $0 \leq \alpha, \beta \leq 1$, the corresponding copula density is

$$
c(u, v)= \begin{cases}(1-\alpha) u^{-\alpha}, & \text { if } u^{\alpha} \geq v^{\beta}, \\ (1-\beta) v^{-\beta}, & \text { if } u^{\alpha}<v^{\beta} .\end{cases}
$$

Independence of $U$ and $V$ corresponds to $\alpha=\beta=0$. Complete dependence of $U$ and $V$ corresponds to $\alpha=\beta=1$. The Cuadras-Augé copula is the particular case of this copula for $\alpha=\beta$.

\subsubsection{The Cubic copula}

The Cubic copula due to Durrleman et al. [20] defined by

$$
C(u, v)=u v[1+\theta(u-1)(v-1)(2 u-1)(2 v-1)] .
$$

For $-1 \leq \theta \leq 2$, the corresponding copula density is

$$
c(u, v)=1+\theta-6 \theta(u+v)+6 \theta\left(u^{2}+v^{2}\right)-36 \theta u v(u+v)+36 \theta u v(1+u v) .
$$

Independence of $U$ and $V$ corresponds to $\theta=0$.

\subsubsection{The Gumbel copula}

The Gumbel copula due to Gumbel [27] defined by

$$
C(u, v)=u+v-1+(1-u)(1-v) \exp [-\theta \ln (1-u) \ln (1-v)]
$$

For $0 \leq \theta \leq 1$, the corresponding copula density is 


$$
\begin{gathered}
c(u, v)=\left[1-\theta-\theta \ln (1-u)-\theta \ln (1-v)+\theta^{2} \ln (1-u) \ln (1-v)\right] \\
. \exp \{-\theta \ln (1-u) \ln (1-v)\} .
\end{gathered}
$$

Independence of $U$ and $V$ corresponds to $\theta=0$.

\subsubsection{The Joe copula}

The Joe copula due to Joe [33] defined by

$$
C(u, v)=1-\left[(1-u)^{\theta}+(1-v)^{\theta}-(1-u)^{\theta}(1-v)^{\theta}\right]^{1 / \theta} .
$$

For $1 \leq \theta<\infty$, the corresponding copula density is

$$
\begin{gathered}
c(u, v)=(1-u)^{\theta-1}(1-v)^{\theta-1}\left[(1-u)^{\theta}+(1-v)^{\theta}-(1-u)^{\theta}(1-v)^{\theta}\right]^{1 / \theta-2} \\
\cdot\left[(1-u)^{\theta}+(1-v)^{\theta}-(1-u)^{\theta}(1-v)^{\theta}+\theta-1\right] .
\end{gathered}
$$

Independence of $U$ and $V$ corresponds to $\theta=1$.

Note that the $\mathrm{t}$ and Marshall-Olkin copulas have two parameters each. The remaining copulas have one parameter each.

To fit these ten models to stock data from two countries at time, the following procedure are followed: let $x_{1}, x_{2}, \ldots, x_{n}$ denote the log returns of the stock for one of the country and $y_{1}, y_{2}, \ldots, y_{n}$ denote the log returns of the stock for the other country; transform $u_{i}=\operatorname{rank}\left(x_{i}\right) /(n+1)$ and $v_{i}=\operatorname{rank}\left(y_{i}\right) /(n+1)$; fit the copula by the method of maximum likelihood to the data on $\left(u_{i}, v_{i}\right) ; i=1,2, \ldots, n$. this amounts to maximizing the likelihood

$$
L(\Theta)=\prod_{i=1}^{n} c\left(u_{i}, v_{i} ; \Theta\right)
$$

or the log-likelihood

$$
\ln L(\Theta)=\sum_{i=1}^{n} \ln c\left(u_{i}, v_{i} ; \Theta\right),
$$

where $\Theta=\left(\theta_{1}, \theta_{2}, \ldots, \theta_{k}\right)$ is a vector of parameters specifying $c(.,$.$) . We shall let \widehat{\Theta}=$ $\left(\widehat{\theta_{1}}, \widehat{\theta_{2}}, \ldots, \widehat{\theta_{k}}\right)$ denotes the maximum likelihood estimate of $\Theta$. The maximization was 
performed using the routine nlm in the R software package (R Development Core Team, 2020). The standard errors of $\widehat{\Theta}$ were computed by approximating the covariance matrix of $\widehat{\Theta}$ by the inverse of observed information matrix, i.e.,

$$
\operatorname{Cov}(\widehat{\Theta}) \approx\left(\begin{array}{lll}
\frac{\partial^{2} \ln L}{\partial \theta_{1}^{2}} & \frac{\partial^{2} \ln L}{\partial \theta_{1} \partial \theta_{2}} \cdots & \frac{\partial^{2} \ln L}{\partial \theta_{1} \partial \theta_{k}} \\
\frac{\partial^{2} \ln L}{\partial \theta_{2} \partial \theta_{1}} & \frac{\partial^{2} \ln L}{\partial \theta_{2}^{2}} \cdots & \frac{\partial^{2} \ln L}{\partial \theta_{2} \partial \theta_{k}} \\
\vdots & \vdots \\
\frac{\partial^{2} \ln L}{\partial \theta_{k} \partial \theta_{1}} & \frac{\partial^{2} \ln L}{\partial \theta_{k} \partial \theta_{2}} & \frac{\partial^{2} \ln L}{\partial \theta_{k}^{2}}
\end{array}\right)_{\Theta=\Theta}^{-1} .
$$

Discrimination among the fitted models was performed using various criteria:

- The Akaike information criterion due to Akaike [2] defined by

$$
\mathrm{AIC}=2 k-2 \ln L(\widehat{\Theta}) ;
$$

- The Bayesian information criterion due to Schwarz [42] defined by

$$
\mathrm{BIC}=k \ln n-2 \ln L(\widehat{\Theta}) ;
$$

- The consistent Akaike information criterion(CAIC) due to Bozdogan [9] defined by

$$
\mathrm{CAIC}=-2 \ln L(\widehat{\Theta})+k(\ln n+1)
$$

- The corrected Akaike information criterion (AICc) due to Hurvich and Tsai [32] defined by

$$
\mathrm{AICc}=\mathrm{AIC}+\frac{2 k(k+1)}{n-k-1} ;
$$

- The Hannan-Quinn criterion due to Hannan and Quinn [28] defined by

$$
\mathrm{HQC}=-2 \ln L(\widehat{\Theta})+2 k \ln \ln n .
$$

The smaller the value of the criteria the better the fit. For more discussion on these criteria, see Burnham and Anderson [10] and Fang [23]. 


\section{Analysis and Results}

From the processed data (using equation 1), which is the logarithmic difference of the daily closing index values, the series of daily returns over non-overlapping successive selection intervals were obtained. The following summary statistics for the daily log returns are computed and given in Table 3.1: number of observations (n), the minimum (Min), first quartile (Q1), median, mean, third quartile (Q3), the maximum (Max), standard deviation, coefficient of variation $(\mathrm{CV})$, skewness, kurtosis, interquartile range (IQR), range and variance.

Table 1. Descriptive statistics of daily log returns for the period 2003-2018 for the Egypt, Nigeria, South Africa, and Kenya stock markets.

\begin{tabular}{llllll}
\hline Region & Statistics & EGY & NGR & SA & KEN \\
\hline African stock & $\mathrm{n}$ & 3200 & 3200 & 3200 & 3200 \\
Markets & Min & -4.880034 & -4.855714 & -4.867219 & -4.899312 \\
& Q1 & -1.956204 & -1.953400 & -1.952901 & -1.955992 \\
& Median & -0.823661 & -0.819936 & -0.821138 & -0.817985 \\
& Mean & 0.001136 & -0.001014 & 0.001874 & -0.000296 \\
& Q3 & 2.050203 & 2.054370 & 2.055497 & 2.053494 \\
& Max & 5.760113 & 5.750136 & 5.758117 & 5.822058 \\
& SD & 2.884172 & 2.876822 & 2.875992 & 2.876261 \\
& CV & $2.539024 \times 10^{3}$ & $-2.838366 \times 10^{3}$ & $-2.838366 \times 10^{3}$ & $-9.709959 \times 10^{3}$ \\
& Skewness & 0.438087 & 0.449077 & 0.446973 & 0.440617 \\
& Kurtosis & -0.818216 & -0.801830 & -0.807303 & -0.810961 \\
& IQR & 4.006407 & 4.00777 & 4.008398 & 4.009486 \\
& Range & 10.64015 & 10.60585 & 10.62534 & 10.72137 \\
& Variance & 8.318451 & 8.276105 & 8.271330 & 8.272878 \\
\cline { 2 - 5 } & & & &
\end{tabular}

Table 2. Descriptive statistics of daily $\log$ returns for period 2003-2018 for the FTSE100(UK), S\&P500(US), DAX(Germany), and CAC40(Canada) stock markets.

\begin{tabular}{llllll}
\hline Region & Statistics & FTSE100 & S\&P500 & DAX & CAC40 \\
\hline Developed & $\mathrm{n}$ & 3200 & 3200 & 3200 & 3200 \\
stock Markets & Min & -4.875787 & -4.884073 & -4.867334 & -4.854716 \\
& Q1 & -1.960951 & -1.958513 & -1.960432 & -1.959067 \\
& Median & -0.825349 & -0.823479 & -0.832005 & -0.826930 \\
& Mean & 0.000861 & 0.000191 & 0.000191 & 0.000643 \\
& Q3 & 2.060841 & 2.052970 & 2.053530 & 2.050269 \\
& Max & 5.808555 & 5.802305 & 5.810057 & 5.774394 \\
& SD & 2.885481 & 2.883154 & 2.886818 & 2.880741 \\
& CV & $3.350895 \times 10^{3}$ & $1.508616 \times 10^{4}$ & $1.508874 \times 10^{4}$ & $4.478388 \times 10^{3}$ \\
& Skewness & 0.434958 & 0.439833 & 0.446592 & 0.444802 \\
& Kurtosis & -0.825809 & -0.815856 & -0.814897 & -0.813456 \\
& IQR & 4.021792 & 4.011483 & 4.013962 & 4.009336 \\
& Range & 10.68434 & 10.68638 & 10.67739 & 10.62911 \\
& Variance & 8.325999 & 8.312574 & 8.333717 & 8.298669 \\
\hline
\end{tabular}


From the Tables 1 and 2, as expected, the minimum values and values of the first quartile are negative for the eight countries. The smallest of the minimum is for KEN. The largest of the minimum is for CAC40. The smallest of the first quartile is for FTSE100. The largest of the first quartile is for NGR. The values of the mean are all positive and close to zero for the countries except for NGR and KEN. The values of the median are all negative and close to zero for the eight countries. The median is largest for KEN and smallest for DAX. The mean is smallest for KEN and largest for FTSE100. The third quartile is smallest for FTSE100 and largest for EGY. The maximum is smallest for NGR and largest for KEN. The inter quartile range is smallest for EGY and largest for FTSE100. The range is smallest for NGR and largest for KEN. The standard deviation is smallest for SA and largest for DAX. The variance is also smallest for SA and largest for DAX. The skewness is positive for all the four countries. The log returns are least skewed for FTSE100. The log returns are most skewed for NGR. The kurtosis is smaller than that for the normal distribution for all countries. The kurtosis is smallest for FTSE100. The kurtosis is largest for NGR. The values of the coefficient of variation are generally positive for all the developed markets and negative for the African markets with exception of EGY. The coefficient of variation is smallest for KEN and largest for the CAC40.

The ten models were fitted to log returns from two of the countries at a time. There are eight countries. So, the ten models were fitted to log returns from the twenty eight pairs of countries: EGY/NGR, EGY/SA, EGY/KEN, EGY/FTSE100, EGY/SP500, EGY/DAX, EGY/CAC40， NGR/SA， NGR/KEN， NGR/FTSE100， NGR/SP500, NGR/DAX, NGR/CAC40, SA/KEN, SA/FTSE100, SA/SP500, SA/DAX, SA/CAC40, KEN/FTSE100, KEN/SP500, KEN/DAX, KEN/CAC40, FTSE100/SP500, FTSE100/DAX, FTSE100/CAC40, SP500/DAX, SP500/CAC40, DAX/CAC40. The method of maximum likelihood was used. The log-likelihood values, the AIC values, the BIC values, the CAIC values, the AICc values and the HQC values for the fitted models are given in Tables 3 to 30 . 
Table 3. Fitted models, log-likelihood values and selection criteria for EGY/NGR.

\begin{tabular}{lllllll}
\hline Model & - In L & AIC & BIC & CAIC & AICc & HQC \\
\hline T & -76.4 & -148.8 & -136.6 & -134.6 & -148.8 & -144.4 \\
AMH & -74.5 & -146.9 & -140.8 & -139.8 & -146.9 & -144.7 \\
Clayton & -316.1 & -630.2 & -624.1 & -623.1 & -630.2 & -628.0 \\
Joe & 0.0 & 2.0 & 8.1 & 9.1 & 2.0 & 4.2 \\
Gumbel & -4425.8 & -8849.7 & -8843.6 & -8842.6 & -8849.7 & -8847.5 \\
FGM & -122.6 & -243.3 & -237.2 & -236.2 & -243.3 & -241.1 \\
Cuadras-Auge & 0.0 & 2.0 & 8.1 & 9.1 & 2.0 & 4.2 \\
Marshall-Olkin & 0.0 & 4.0 & 16.1 & 18.1 & 4.0 & 8.4 \\
Cubic & -131.1 & -260.1 & -254.0 & -253.0 & -260.1 & -257.9 \\
Guassian & -45.2 & -88.4 & -82.3 & -81.3 & -88.4 & -86.2 \\
\hline
\end{tabular}

Table 4. Fitted models, log-likelihood values and selection criteria for EGY/SA.

\begin{tabular}{lllllll}
\hline Model & - In L & AIC & BIC & CAIC & AICc & HQC \\
\hline T & -166.9 & -329.7 & -317.6 & -315.6 & -329.7 & -325.3 \\
AMH & -127.8 & -253.5 & -247.4 & -246.4 & -253.5 & -251.3 \\
Clayton & -94.1 & -186.2 & -180.2 & -179.2 & -186.2 & -184.0 \\
Joe & -90.8 & -179.5 & -173.4 & -172.4 & -179.5 & -177.3 \\
Gumbel & -4778.3 & -9554.6 & -9548.5 & -9547.5 & -9554.6 & -9552.4 \\
FGM & -161.6 & -321.2 & -315.1 & -314.1 & -321.2 & -319.0 \\
Cuadras-Auge & 0.0 & 2.0 & 8.1 & 9.1 & 2.0 & 4.2 \\
Marshall-Olkin & 0.0 & 4.0 & 16.1 & 18.1 & 4.0 & 8.4 \\
Cubic & -7.9 & -13.8 & -7.7 & -6.7 & -13.8 & -11.6 \\
Guassian & 0.0 & 2.0 & 8.0 & 9.1 & 2.0 & 4.2 \\
\hline
\end{tabular}

Table 5. Fitted models, log-likelihood values and selection criteria for EGY/KEN.

\begin{tabular}{lllllll}
\hline Model & - In L & AIC & BIC & CAIC & AICc & HQC \\
\hline T & -172.8 & -341.6 & -329.5 & -327.5 & -341.5 & -337.3 \\
AMH & -147.1 & -292.1 & -286.0 & -285.0 & -292.1 & -289.9 \\
Clayton & 4.5 & 11.1 & 17.2 & 18.2 & 11.1 & 13.3 \\
Joe & 0.0 & 20. & 8.1 & 9.1 & 2.0 & 4.2 \\
Gumbel & -5650.6 & -11299.2 & -11293.2 & -11292.2 & -11299.2 & -11297.1 \\
FGM & -126.2 & -250.5 & -244.4 & -243.4 & -250.5 & -248.3 \\
Cuadras-Auge & 0.0 & 2.0 & 8.1 & 9.1 & 2.0 & 4.2 \\
Marshall-Olkin & 0.0 & 4.0 & 16.1 & 18.1 & 4.0 & 8.4 \\
Cubic & -165.5 & -329.1 & -323.0 & -322.0 & -329.1 & -326.9 \\
Guassian & -157.9 & -313.9 & -307.8 & -306.8 & -313.9 & -311.7 \\
\hline
\end{tabular}


Table 6. Fitted models, log-likelihood values and selection criteria for EGY/FTSE.

\begin{tabular}{lllllll}
\hline Model & - In L & AIC & BIC & CAIC & AICc & HQC \\
\hline T & -93.1 & -182.1 & -170.0 & -168.0 & -182.1 & -177.8 \\
AMH & -139.7 & -277.4 & -271.3 & -270.3 & -277.4 & -275.2 \\
Clayton & -520.1 & -1038.2 & -1032.1 & -1031.1 & -1038.2 & -1036.0 \\
Joe & 0.0 & 2.0 & 8.1 & 9.1 & 2.0 & 4.2 \\
Gumbel & -4183.2 & -8364.4 & -8358.4 & -8357.4 & -8364.4 & -8362.3 \\
FGM & -240.6 & -479.1 & -473.0 & -472.0 & -479.1 & -476.9 \\
Cuadras-Auge & 0.0 & 2.0 & 8.1 & 9.1 & 2.0 & 4.2 \\
Marshall-Olkin & 0.0 & 4.0 & 16.1 & 18.1 & 4.0 & 8.4 \\
Cubic & -332.2 & -662.5 & -656.4 & -655.4 & -662.5 & -660.3 \\
Guassian & -72.7 & -143.4 & -137.4 & -136.4 & -143.4 & -141.2 \\
\hline
\end{tabular}

Table 7. Fitted models, log-likelihood values and selection criteria for EGY/S\&P500.

\begin{tabular}{lllllll}
\hline Model & - In L & AIC & BIC & CAIC & AICc & HQC \\
\hline T & -174.5 & -345.0 & -332.8 & -330.8 & -345.0 & -340.6 \\
AMH & -148.4 & -294.8 & -288.8 & -287.8 & -294.8 & -292.6 \\
Clayton & 4.5 & 11.0 & 17.0 & 18.0 & 11.0 & 13.1 \\
Joe & 0.0 & 2.0 & 8.1 & 9.1 & 2.0 & 4.2 \\
Gumbel & -5659.6 & -11317.1 & -11311.0 & -11310.0 & -11317.1 & -11314.9 \\
FGM & -125.7 & -249.5 & -243.4 & -242.4 & -249.5 & -247.3 \\
Cuadras-Auge & 0.0 & 2.0 & 8.1 & 9.1 & 2.0 & 4.2 \\
Marshall-Olkin & 0.0 & 4.0 & 16.1 & 18.1 & 4.0 & 8.4 \\
Cubic & -169.9 & -337.8 & -331.8 & -330.8 & -337.8 & -335.7 \\
Guassian & -160.7 & -319.4 & -313.3 & -312.3 & -319.4 & -317.2 \\
\hline
\end{tabular}

Table 8. Fitted models, log-likelihood values and selection criteria for EGY/DAX.

\begin{tabular}{lllllll}
\hline Model & - In L & AIC & BIC & CAIC & AICc & HQC \\
\hline T & -174.8 & -345.5 & -333.4 & -331.4 & -345.5 & -341.2 \\
AMH & -132.6 & -263.1 & -257.1 & -256.1 & -263.1 & -261.0 \\
Clayton & -95.6 & -189.1 & -183.1 & -182.1 & -189.1 & -187.0 \\
Joe & -95.7 & -189.4 & -183.4 & -182.4 & -189.4 & -187.3 \\
Gumbel & -4771.8 & -9541.6 & -9535.5 & -9534.5 & -9541.6 & -9539.4 \\
FGM & -172.8 & -343.7 & -337.6 & -336.6 & -343.7 & -341.5 \\
Cuadras-Auge & 0.0 & 2.0 & 8.1 & 9.1 & 2.0 & 4.2 \\
Marshall-Olkin & 0.0 & 4.0 & 16.1 & 18.1 & 4.0 & 8.4 \\
Cubic & -9.4 & -16.8 & -10.7 & -9.7 & -16.8 & -14.6 \\
Guassian & 0.0 & 2.0 & 8.0 & 9.0 & 2.0 & 4.2 \\
\hline
\end{tabular}


Table 9. Fitted models, log-likelihood values and selection criteria for EGY/CAC.

\begin{tabular}{lllllll}
\hline Model & $-\mathrm{In} \mathrm{L}$ & AIC & BIC & CAIC & AICc & HQC \\
\hline $\mathrm{t}$ & -69.5 & -135.0 & -122.9 & -120.9 & -135.0 & -130.7 \\
AMH & -68.1 & -134.2 & -128.1 & -127.1 & -134.2 & -132.0 \\
Clayton & -317.1 & -632.2 & -626.1 & -625.1 & -632.2 & -630.0 \\
Joe & 0.0 & 2.0 & 8.1 & 9.1 & 2.0 & 4.2 \\
Gumbel & -4436.8 & -8871.6 & -8865.5 & -8864.5 & -8871.6 & -8869.4 \\
FGM & -107.6 & -213.1 & -207.1 & -206.1 & -213.1 & -210.9 \\
Cuadras-Auge & 0.0 & 2.0 & 8.1 & 9.1 & 2.0 & 4.2 \\
Marshall-Olkin & 0.0 & 4.0 & 16.2 & 18.2 & 4.0 & 8.4 \\
Cubic & -117.7 & -233.4 & -227.4 & -226.4 & -233.4 & -231.3 \\
Guassian & -37.4 & -72.8 & -66.7 & -65.7 & -72.8 & -70.6 \\
\hline
\end{tabular}

Table 10. Fitted models, log-likelihood values and selection criteria for NGR/SA.

\begin{tabular}{lllllll}
\hline Model & - In L & AIC & BIC & CAIC & AICc & HQC \\
\hline $\mathrm{t}$ & -75.4 & -146.9 & -134.8 & -132.8 & -146.9 & -142.5 \\
AMH & -72.6 & -143.3 & -137.2 & -136.2 & -143.3 & -141.1 \\
Clayton & -318.1 & -634.2 & -628.1 & -627.1 & -634.2 & -632.0 \\
Joe & 0.0 & 2.0 & 8.1 & 9.1 & 2.0 & 4.2 \\
Gumbel & -4426.5 & -8851.0 & -8845.0 & -8844.0 & -8851.0 & -8848.8 \\
FGM & -119.1 & -236.1 & -230.1 & -229.1 & -236.1 & -234.0 \\
Cuadras-Auge & 0.0 & 2.0 & 8.1 & 9.1 & 2.0 & 4.2 \\
Marshall-Olkin & 0.0 & 4.0 & 16.1 & 18.1 & 4.0 & 8.4 \\
Cubic & -128.3 & -254.7 & -248.6 & -247.6 & -254.7 & -252.5 \\
Guassian & -44.5 & -86.9 & -80.8 & -79.8 & -86.9 & -84.7 \\
\hline
\end{tabular}

Table 11. Fitted models, log-likelihood values and selection criteria for NGR/KEN.

\begin{tabular}{lllllll}
\hline Model & - In L & AIC & BIC & CAIC & AICc & HQC \\
\hline $\mathrm{t}$ & -166.7 & -329.4 & -317.3 & -315.3 & -329.4 & -325.1 \\
AMH & -127.3 & -252.6 & -246.6 & 245.6 & -252.6 & -250.5 \\
Clayton & -94.0 & -186.1 & -180.0 & -179.0 & -186.1 & -183.9 \\
Joe & -90.3 & -178.5 & -172.5 & -171.5 & -178.5 & -176.3 \\
Gumbel & -4782.0 & -9862.1 & -9556.0 & -9555.0 & -9562.1 & -9559.9 \\
FGM & -161.3 & -320.7 & -314.6 & -313.6 & -320.7 & -318.5 \\
Cuadras-Auge & 0.0 & 2.0 & 8.1 & 9.1 & 2.0 & 4.2 \\
Marshall-Olkin & 0.0 & 4.0 & 16.1 & 18.1 & 4.0 & 8.4 \\
Cubic & -7.8 & -13.6 & -7.5 & -6.5 & -13.6 & -11.4 \\
Guassian & 0.0 & 2.0 & 8.1 & 9.1 & 2.0 & 4.2 \\
\hline
\end{tabular}


Table 12. Fitted models, log-likelihood values and selection criteria for NGR/FTSE.

\begin{tabular}{lllllll}
\hline Model & -In L & AIC & BIC & CAIC & AICc & HQC \\
\hline $\mathrm{t}$ & -170.4 & -336.7 & -324.6 & -322.6 & -336.7 & -332.4 \\
AMH & -143.0 & -283.9 & -277.8 & -276.8 & -283.9 & -281.7 \\
Clayton & 4.5 & 11.0 & 17.0 & 18.0 & 11.0 & 13.1 \\
Joe & 0.0 & 2.0 & 8.1 & 9.1 & 2.0 & 4.2 \\
Gumbel & -5655.3 & -11308.6 & -11302.5 & -11301.5 & -11308.6 & -11306.4 \\
FGM & -121.9 & -241.9 & -235.8 & -234.8 & -241.9 & -239.7 \\
Cuadras-Auge & 0.0 & 2.0 & 8.1 & 9.1 & 2.0 & 4.2 \\
Marshall-Olkin & 0.0 & 4.0 & 16.1 & 18.1 & 4.0 & 8.4 \\
Cubic & -167.7 & -333.4 & -327.3 & -326.3 & -333.4 & -331.2 \\
Guassian & 153.0 & -304.0 & -297.9 & -296.9 & -304.0 & -301.8 \\
\hline
\end{tabular}

Table 13. Fitted models, log-likelihood values and selection criteria for NGR/S\&P.

\begin{tabular}{lllllll}
\hline Model & - In L & AIC & BIC & CAIC & AICc & HQC \\
\hline $\mathrm{t}$ & -95.9 & -187.7 & -175.6 & -173.6 & -187.7 & -183.4 \\
AMH & -143.9 & -285.9 & -279.8 & -278.8 & -285.9 & -283.7 \\
Clayton & -516.1 & -1030.2 & -1024.1 & -1023.1 & 1030.2 & 1028.0 \\
Joe & 0.0 & 2.0 & 8.1 & 9.1 & 2.0 & 4.2 \\
Gumbel & -4191.3 & -8380.6 & -8374.6 & -8373.6 & -8380.6 & -8378.5 \\
FGM & -244.9 & -487.9 & -481.8 & 480.8 & 487.8 & -485.7 \\
Cuadras-Auge & 0.0 & 2.0 & 8.1 & 9.1 & 2.0 & 4.2 \\
Marshall-Olkin & 0.0 & 4.0 & 16.2 & 18.2 & 4.0 & 8.4 \\
Cubic & -331.1 & -660.2 & -654.1 & -653.1 & -660.2 & -658.0 \\
Guassian & -76.3 & -150.6 & -144.5 & -143.5 & 150.6 & -148.4 \\
\hline
\end{tabular}

Table 14. Fitted models, log-likelihood values and selection criteria for NGR/DAX.

\begin{tabular}{lllllll}
\hline Model & - In L & AIC & BIC & CAIC & AICc & HQC \\
\hline $\mathrm{t}$ & -174.7 & -345.4 & -333.2 & -331.2 & -345.4 & $341.4-0$ \\
AMH & -148.5 & -295.1 & -289.0 & -288.0 & -295.1 & -292.9 \\
Clayton & 4.5 & 11.1 & 17.1 & 18.1 & 11.1 & 13.2 \\
Joe & 0.0 & 2.0 & 8.1 & 9.1 & 2.0 & 4.2 \\
Gumbel & -5656.9 & -11311.8 & -11305.7 & -11304.7 & -11311.8 & -11309.6 \\
FGM & -127.1 & -252.2 & -246.1 & -245.1 & -252.2 & 250.0 \\
Cuadras-Auge & 0.0 & 2.0 & 8.1 & 9.1 & 2.0 & 4.2 \\
Marshall-Olkin & 0.0 & 4.0 & 16.2 & 18.2 & 4.0 & 8.4 \\
Cubic & -162.5 & -323.0 & -316.9 & -315.9 & -323.0 & -320.8 \\
Guassian & -160.4 & -318.9 & -312.8 & -311.8 & -318.9 & -316.7 \\
\hline
\end{tabular}


Table 15. Fitted models, log-likelihood values and selection criteria for NGR/CAC.

\begin{tabular}{lllllll}
\hline Model & $-\mathrm{In} \mathrm{L}$ & AIC & BIC & CAIC & AICc & HQC \\
\hline $\mathrm{t}$ & -172.8 & -341.6 & -329.4 & -327.4 & -341.6 & -337.2 \\
AMH & -133.7 & -265.3 & -259.2 & -258.2 & -265.3 & -263.1 \\
Clayton & -97.6 & -193.1 & -187.0 & -186.0 & -193.1 & -190.9 \\
Joe & -94.5 & -187.1 & -181.0 & -180.0 & -187.1 & -184.9 \\
Gumbel & -4777.1 & -9552.3 & -9546.2 & -9545.2 & -9552.3 & -9550.1 \\
FGM & -170.0 & -338.0 & -331.9 & -330.9 & -338.0 & -335.8 \\
Cuadras-Auge & 0.0 & 2.0 & 8.1 & 9.1 & 2.0 & 4.2 \\
Marshall-Olkin & 0.0 & 4.0 & 16.1 & 18.1 & 4.0 & 8.4 \\
Cubic & -7.9 & -13.8 & -7.7 & -6.7 & -13.8 & -11.6 \\
Guassian & 0.0 & 2.0 & 8.1 & 9.1 & 2.0 & 4.2 \\
\hline
\end{tabular}

Table 16. Fitted models, log-likelihood values and selection criteria for SA/KEN.

\begin{tabular}{lllllll}
\hline Model & - In L & AIC & BIC & CAIC & AICc & HQC \\
\hline $\mathrm{t}$ & -77.4 & -150.8 & -138.7 & -136.7 & -150.8 & -146.4 \\
AMH & -74.6 & -147.3 & -141.2 & -140.2 & -147.3 & -145.1 \\
Clayton & -124.9 & -247.9 & -241.8 & -240.8 & -247.9 & -245.7 \\
Joe & 0.0 & 2.0 & 8.1 & 9.1 & 2.0 & 4.2 \\
Gumbel & -4428.8 & -8855.6 & -8849.5 & -8848.5 & -8855.6 & -8853.4 \\
FGM & -123.0 & -243.9 & -237.9 & -236.9 & -243.9 & -241.8 \\
Cuadras-Auge & 0.0 & 2.0 & 8.1 & 9.1 & 2.0 & 4.2 \\
Marshall-Olkin & 0.0 & 4.0 & 16.1 & 18.1 & 4.0 & 8.4 \\
Cubic & -128.9 & -255.7 & -249.6 & -248.6 & -255.7 & -253.5 \\
Guassian & -45.3 & -88.6 & -82.5 & -81.5 & -88.6 & -86.4 \\
\hline
\end{tabular}

Table 17. Fitted models, log-likelihood values and selection criteria for SA/FTSE.

\begin{tabular}{lllllll}
\hline Model & - In L & AIC & BIC & CAIC & AICc & HQC \\
\hline T & -171.3 & -338.7 & -326.5 & -324.5 & -338.7 & -334.3 \\
AMH & -131.6 & -261.2 & -255.1 & -254.1 & -261.2 & -259.0 \\
Clayton & -96.9 & -191.8 & -185.7 & -184.7 & -191.8 & -189.6 \\
Joe & -92.4 & -182.8 & -176.7 & -175.7 & -182.8 & -180.6 \\
Gumbel & -4783.2 & -9564.5 & -9558.4 & -9557.4 & -9564.5 & -9562.3 \\
FGM & -167.0 & -332.0 & -325.9 & -324.9 & -332.0 & -329.8 \\
Cuadras-Auge & 0.0 & 2.0 & 8.1 & 9.1 & 2.0 & 4.2 \\
Marshall-Olkin & 0.0 & 4.0 & 16.1 & 18.1 & 4.0 & 8.4 \\
Cubic & -7.6 & -13.2 & -7.1 & -6.1 & -13.2 & -11.0 \\
Guassian & 0.0 & 2.0 & 8.1 & 9.1 & 2.0 & 4.2 \\
\hline
\end{tabular}


Table 18. Fitted models, log-likelihood values and selection criteria for SA/S\&P.

\begin{tabular}{lllllll}
\hline Model & - In L & AIC & BIC & CAIC & AICc & HQC \\
\hline T & -168.5 & -332.9 & -320.8 & -318.8 & -332.9 & -328.6 \\
AMH & -144.4 & -286.7 & -280.6 & -279.6 & -286.7 & -284.5 \\
Clayton & 4.5 & 11.0 & 17.1 & 18.1 & 11.0 & 13.2 \\
Joe & 0.0 & 2.0 & 8.1 & 9.1 & 2.0 & 4.2 \\
Gumbel & -5634.4 & -11266.9 & -11260.8 & -11259.8 & -11266.9 & -11264.7 \\
FGM & -124.1 & -246.1 & -240.1 & -239.1 & -246.1 & -243.9 \\
Cuadras-Auge & 0.0 & 2.0 & 8.1 & 9.1 & 2.0 & 4.2 \\
Marshall-Olkin & 0.0 & 4.0 & 16.1 & 18.1 & 4.0 & 8.4 \\
Cubic & -155.8 & -309.6 & -303.6 & -302.6 & -309.6 & -307.5 \\
Guassian & -153.3 & -304.6 & -298.5 & -297.5 & -304.6 & -302.4 \\
\hline
\end{tabular}

Table 19. Fitted models, log-likelihood values and selection criteria for SA/DAX.

\begin{tabular}{lllllll}
\hline Model & - In L & AIC & BIC & CAIC & AICc & HQC \\
\hline T & -95.5 & -186.9 & -174.8 & -172.8 & -186.9 & -182.6 \\
AMH & -143.0 & -283.9 & -277.8 & -276.8 & -283.9 & -281.7 \\
Clayton & -512.1 & -1022.2 & -1016.1 & -1015.1 & -1022.2 & -1020.0 \\
Joe & 0.0 & 2.0 & 8.1 & 9.1 & 2.0 & 4.2 \\
Gumbel & -4188.4 & -8374.7 & -8368.6 & -8367.6 & -8374.7 & -8372.5 \\
FGM & -244.4 & -486.7 & -480.7 & -479.7 & -486.7 & -484.6 \\
Cuadras-Auge & 0.0 & 2.0 & 8.1 & 9.1 & 2.0 & 4.2 \\
Marshall-Olkin & 0.0 & 4.0 & 16.1 & 18.1 & 4.0 & 8.4 \\
Cubic & -330.5 & -658.9 & -652.9 & -651.9 & -658.9 & -656.8 \\
Guassian & -73.6 & -145.2 & -139.2 & -138.2 & -145.2 & -143.1 \\
\hline
\end{tabular}

Table 20. Fitted models, log-likelihood values and selection criteria for SA/CAC.

\begin{tabular}{lllllll}
\hline Model & - In L & AIC & BIC & CAIC & AICc & HQC \\
\hline T & -174.7 & -345.3 & -333.2 & -331.2 & -345.3 & -341.0 \\
AMH & -146.0 & -290.0 & -283.9 & -282.9 & -290.0 & -287.8 \\
Clayton & 4.5 & 11.0 & 17.1 & 18.0 & 11.0 & 13.2 \\
Joe & 0.0 & 2.0 & 8.1 & 9.1 & 2.0 & 4.2 \\
Gumbel & -5664.2 & -11326.5 & -11320.4 & -11319.4 & -11326.5 & -11324.3 \\
FGM & -125.1 & -248.1 & -242.0 & -241.0 & -248.1 & -245.9 \\
Cuadras-Auge & 0.0 & 2.0 & 8.1 & 9.1 & 2.0 & 4.2 \\
Marshall-Olkin & 0.0 & 4.0 & 16.1 & 18.1 & 4.0 & 8.4 \\
Cubic & -171.2 & -340.3 & -334.2 & -333.2 & -340.3 & -338.1 \\
Guassian & -152.6 & -303.1 & -297.0 & -296.0 & -303.1 & -300.9 \\
\hline
\end{tabular}


Table 21. Fitted models, log-likelihood values and selection criteria for KEN/FTSE.

\begin{tabular}{lllllll}
\hline Model & - In L & AIC & BIC & CAIC & AICc & HQC \\
\hline T & -73.7 & -143.4 & -131.3 & -129.3 & -143.4 & -139.1 \\
AMH & -70.7 & -139.3 & -133.3 & -132.3 & -139.3 & -137.2 \\
Clayton & -325.1 & -648.2 & -642.1 & -641.1 & -648.2 & -646.0 \\
Joe & 0.0 & 2.0 & 8.1 & 9.1 & 2.0 & 4.2 \\
Gumbel & -4421.4 & -8840.8 & -8834.7 & -8833.7 & -8840.8 & -8838.6 \\
FGM & -116.8 & -231.6 & -225.6 & -224.6 & -231.6 & -229.5 \\
Cuadras-Auge & 0.0 & 2.0 & 8.1 & 9.1 & 2.0 & 4.2 \\
Marshall-Olkin & 0.0 & 4.0 & 16.2 & 18.2 & 4.0 & 8.4 \\
Cubic & -130.4 & -258.8 & -252.7 & -251.7 & -258.8 & -256.6 \\
Guassian & -42.7 & -83.4 & -77.3 & -76.3 & -83.4 & -81.2 \\
\hline
\end{tabular}

Table 22. Fitted models, log-likelihood values and selection criteria for KEN/S\&P.

\begin{tabular}{lllllll}
\hline Model & - In L & AIC & BIC & CAIC & AICc & HQC \\
\hline T & -164.9 & -325.8 & -313.7 & -311.7 & -325.8 & -321.5 \\
AMH & -128.8 & -255.5 & -249.5 & -248.5 & -255.5 & -253.4 \\
Clayton & -95.4 & -188.7 & -182.7 & -181.7 & -188.7 & -186.5 \\
Joe & -90.0 & -177.9 & -171.8 & -170.8 & -177.9 & -175.7 \\
Gumbel & -4793.6 & -9585.3 & -9579.2 & -9578.2 & -9585.3 & -9583.1 \\
FGM & -158.0 & -313.9 & -307.8 & -306.8 & -313.9 & -311.7 \\
Cuadras-Auge & 0.0 & 2.0 & 8.1 & 9.1 & 2.0 & 4.2 \\
Marshall-Olkin & 0.0 & 4.0 & 16.1 & 18.1 & 4.0 & 8.4 \\
Cubic & -6.0 & -9.9 & -3.8 & -2.8 & -9.9 & -7.7 \\
Guassian & 0.0 & 2.0 & 8.1 & 9.1 & 2.0 & 4.2 \\
\hline
\end{tabular}

Table 23. Fitted models, log-likelihood values and selection criteria for KEN/DAX.

\begin{tabular}{lllllll}
\hline Model & - In L & AIC & BIC & CAIC & AICc & HQC \\
\hline T & -165.7 & -327.4 & -315.2 & -313.2 & -327.4 & -323.0 \\
AMH & -144.0 & -286.0 & -280.0 & -279.0 & -286.0 & -283.8 \\
Clayton & 4.5 & 10.9 & 17.0 & 18.0 & 10.9 & 13.1 \\
Joe & 0.0 & 2.0 & 8.1 & 9.1 & 2.0 & 4.2 \\
Gumbel & -5641.7 & -11281.4 & -11275.3 & -11274.3 & -11281.4 & -11279.2 \\
FGM & -123.1 & -244.2 & -238.1 & -237.1 & -244.2 & -242.0 \\
Cuadras-Auge & 0.0 & 2.0 & 8.1 & 9.1 & 2.0 & 4.2 \\
Marshall-Olkin & 0.0 & 4.0 & 16.1 & 18.1 & 4.0 & 8.4 \\
Cubic & -156.8 & -311.7 & -305.6 & -304.6 & -311.7 & -309.5 \\
Guassian & -150.8 & -299.5 & -293.4 & -292.4 & -299.5 & -297.3 \\
\hline
\end{tabular}


Table 24. Fitted models, log-likelihood values and selection criteria for KEN/CAC.

\begin{tabular}{lllllll}
\hline Model & - In L & AIC & BIC & CAIC & AICc & HQC \\
\hline T & -91.6 & -179.1 & -167.0 & -165.0 & -179.1 & -174.8 \\
AMH & -138.6 & -275.1 & -269.1 & -268.1 & -275.1 & -273.0 \\
Clayton & 6.8 & 15.6 & 21.7 & 22.7 & 15.6 & 17.8 \\
Joe & 0.0 & 2.0 & 8.1 & 9.1 & 2.0 & 4.2 \\
Gumbel & -4181.3 & -8360.5 & -8354.5 & -8353.5 & -8360.5 & -8358.4 \\
FGM & -237.7 & -473.4 & -467.3 & -466.3 & -473.4 & -471.2 \\
Cuadras-Auge & 0.0 & 2.0 & 8.1 & 9.1 & 2.0 & 4.2 \\
Marshall-Olkin & 0.0 & 4.0 & 16.2 & 18.2 & 4.0 & 8.4 \\
Cubic & -332.8 & -663.6 & -657.5 & -656.5 & -663.6 & -661.4 \\
Guassian & -73.5 & -145.0 & -138.9 & -137.9 & -145.0 & -142.8 \\
\hline
\end{tabular}

Table 25. Fitted models, log-likelihood values and selection criteria for FTSE/S\&P.

\begin{tabular}{lllllll}
\hline Model & - In L & AIC & BIC & CAIC & AICc & HQC \\
\hline T & -75.6 & -147.3 & -135.2 & -133.2 & -147.3 & -142.9 \\
AMH & -73.5 & -144.9 & -138.9 & -137.9 & -144.9 & -142.8 \\
Clayton & -123.5 & -245.0 & -238.9 & -237.9 & -245.0 & -242.8 \\
Joe & 0.0 & 2.0 & 8.1 & 9.1 & 2.0 & 4.2 \\
Gumbel & -4426.0 & -8850.0 & -8844.0 & -8843.0 & -8850.0 & -8847.9 \\
FGM & -121.5 & -241.0 & -235.0 & -234.0 & -241.0 & -238.9 \\
Cuadras-Auge & 0.0 & 2.0 & 8.1 & 9.1 & 2.0 & 4.2 \\
Marshall-Olkin & 0.0 & 4.0 & 16.2 & 18.2 & 4.0 & 8.4 \\
Cubic & -130.5 & -259.1 & -253.0 & -252.0 & -259.1 & -256.9 \\
Guassian & -43.7 & -85.4 & -79.4 & -78.4 & -85.4 & -83.3 \\
\hline
\end{tabular}

Table 26. Fitted models, log-likelihood values and selection criteria for FTSE/DAX.

\begin{tabular}{lllllll}
\hline Model & - In L & AIC & BIC & CAIC & AICc & HQC \\
\hline T & -165.3 & -326.7 & -314.5 & -312.5 & 326.7 & -322.3 \\
AMH & -126.6 & -251.3 & -245.2 & -244.2 & -251.3 & -249.1 \\
Clayton & -93.0 & -184.1 & -178.0 & -177.0 & -184.1 & -181.9 \\
Joe & -94.9 & -187.9 & -181.8 & -180.8 & -187.9 & -185.7 \\
Gumbel & -4789.5 & -9577.0 & -9570.9 & -9569.9 & -9576.9 & -9574.8 \\
FGM & -158.0 & -314.0 & -307.9 & -306.9 & -314.0 & -311.8 \\
Cuadras-Auge & 0.0 & 2.0 & 8.1 & 9.1 & 2.0 & 4.2 \\
Marshall-Olkin & 0.0 & 4.0 & 16.1 & 18.1 & 4.0 & 8.4 \\
Cubic & -7.2 & -12.4 & -6.3 & -5.3 & -12.4 & -10.2 \\
Guassian & 0.0 & 2.0 & 8.1 & 9.1 & 2.0 & 4.2 \\
\hline
\end{tabular}


Table 27. Fitted models, log-likelihood values and selection criteria for FTSE/CAC.

\begin{tabular}{lllllll}
\hline Model & - In L & AIC & BIC & CAIC & AICc & HQC \\
\hline T & -176.0 & -348.0 & -335.9 & -333.9 & -348.0 & -343.7 \\
AMH & -145.2 & -288.3 & -282.3 & -281.3 & -288.3 & -286.2 \\
Clayton & 4.6 & 11.1 & 17.2 & 18.2 & 11.1 & 13.3 \\
Joe & -0.2 & 1.7 & 7.7 & 8.7 & 1.7 & 3.9 \\
Gumbel & -5640.5 & -11279.1 & -11273.0 & -11272.0 & -11279.1 & -11276.9 \\
FGM & -127.4 & -252.9 & -246.8 & -245.8 & -252.9 & -250.7 \\
Cuadras-Auge & 0.0 & 2.0 & 8.1 & 9.1 & 2.0 & 4.2 \\
Marshall-Olkin & 0.0 & 4.0 & 16.1 & 18.1 & 4.0 & 8.4 \\
Cubic & -159.0 & -315.9 & -309.9 & -308.9 & -315.9 & -313.8 \\
Guassian & -133.9 & -265.7 & -259.6 & -258.6 & -265.7 & -263.5 \\
\hline
\end{tabular}

Table 28. Fitted models, log-likelihood values and selection criteria for S\&P/DAX.

\begin{tabular}{lllllll}
\hline Model & - In L & AIC & BIC & CAIC & AICc & HQC \\
\hline T & -75.3 & -146.5 & -134.4 & -132.4 & -146.5 & -142.2 \\
AMH & -73.0 & -143.9 & -137.9 & -136.9 & -143.9 & -141.8 \\
Clayton & -122.8 & -243.7 & -237.6 & -236.6 & -243.7 & -241.5 \\
Joe & 0.0 & 2.0 & 8.1 & 9.1 & 2.0 & 4.2 \\
Gumbel & -4429.8 & -8857.6 & -8851.6 & -8850.6 & -8857.6 & -8855.5 \\
FGM & -119.9 & -237.7 & -231.6 & -230.6 & -237.7 & -235.5 \\
Cuadras-Auge & 0.0 & 2.0 & 8.1 & 9.1 & 2.0 & 4.2 \\
Marshall-Olkin & 0.0 & 4.0 & 16.2 & 18.2 & 4.0 & 8.4 \\
Cubic & -127.6 & -253.3 & -247.2 & -246.2 & -253.3 & -251.1 \\
Guassian & -43.0 & -84.0 & -77.9 & -76.9 & -84.0 & -81.8 \\
\hline
\end{tabular}

Table 29. Fitted models, log-likelihood values and selection criteria for S\&P/CAC.

\begin{tabular}{lllllll}
\hline Model & - In L & AIC & BIC & CAIC & AICc & HQC \\
\hline T & -165.6 & -327.1 & -315.0 & -313.0 & -327.1 & -322.8 \\
AMH & -127.7 & -253.3 & -247.2 & -246.2 & -253.3 & -251.1 \\
Clayton & -94.3 & -186.6 & -180.5 & -179.5 & -186.6 & -184.4 \\
Joe & -89.5 & -177.0 & -170.9 & -169.9 & -177.0 & -174.8 \\
Gumbel & -4779.2 & -9556.4 & -9550.3 & -9549.3 & -9556.4 & -9554.2 \\
FGM & -161.6 & -321.1 & -315.0 & -314.0 & -321.1 & -318.9 \\
Cuadras-Auge & 0.0 & 2.0 & 8.1 & 9.1 & 2.0 & 4.2 \\
Marshall-Olkin & 0.0 & 4.0 & 16.2 & 18.2 & 4.0 & 8.4 \\
Cubic & -8.4 & -14.9 & -8.8 & -7.8 & -14.8 & -12.7 \\
Guassian & 0.0 & 2.0 & 8.1 & 9.1 & 2.0 & 4.2 \\
\hline
\end{tabular}


Table 30. Fitted models, log-likelihood values and selection criteria for DAX/CAC.

\begin{tabular}{lllllll}
\hline Model & - In L & AIC & BIC & CAIC & AICc & HQC \\
\hline T & -73.8 & -143.7 & -131.5 & -129.5 & -143.7 & -139.3 \\
AMH & -73.4 & -144.9 & -138.8 & -137.8 & -144.9 & -142.7 \\
Clayton & -314.1 & -626.2 & -620.1 & -619.1 & -626.2 & -624.0 \\
Joe & -0.2 & 1.6 & 7.7 & 8.7 & 1.6 & 3.8 \\
Gumbel & -4431.6 & -8861.1 & -8855.0 & -8854.0 & -8861.1 & -8858.9 \\
FGM & -119.4 & -236.8 & -230.7 & -229.7 & -236.8 & -234.6 \\
Cuadras-Auge & 0.0 & 2.0 & 8.1 & 9.1 & 2.0 & 4.2 \\
Marshall-Olkin & 0.0 & 4.0 & 16.1 & 18.1 & 4.0 & 8.4 \\
Cubic & -123.7 & -245.3 & -239.3 & -238.3 & -245.3 & -243.2 \\
Guassian & -34.7 & -67.4 & -61.3 & -60.3 & -67.4 & -65.3 \\
\hline
\end{tabular}

From these tables, it can be observed that the Gumbel copula in spite of having only one parameter gives the smallest values for the negative log-likelihood, the AIC, the BIC, the CAIC, the AICc, and the HQC for every pair. The t copula or the Clayton copula gives the second smallest values for the negative log-likelihood, the AIC, the BIC, the CAIC, the AICc and the HQC for every pair. The Marshall-Olkin copula gives the largest value for the negative log-likelihood, the AIC, the BIC, the CAIC, the AICc and the HQC for every pair. The Cuadras-Augé and Guassian copulas give the second largest values for the negative log-likelihood, the AIC, the BIC, the CAIC, the AICc and the HQC for every pair. The Cuadras-Augé and Guassia copulas appear to give the same values for the negative log-likelihood, the AIC, the BIC, the CAIC, the AICc and the HQC.

The goodness of the best fitting Gumbel copula was tested using the information matrix equality of White [47]. This test was further investigated by Huang and Prokhorov [31]. The contribution is that under correct copula model specification, the Fisher Information can be equivalently calculated as minus the expected Hessian matrix or as the expected outer product of the score function. The p-value shown in Table 31 confirms the goodness of fit of the Gumbel copula. 
Table 31. p-value of the goodness of fit of the best fitting copula (Gumbel) using the information matrix equality test of White [47].

\begin{tabular}{llll}
\hline Pair & p-value & Pair & p-value \\
\hline EGY/NGR & 0.532 & EGY/SA & 0.722 \\
EGY/KEN & 0.621 & EGY/FTSE100 & 0.256 \\
EGY/SP500 & 0.933 & EGY/DAX & 0.662 \\
EGY/CAC40 & 0.754 & NGR/SA & 0.953 \\
NGR/KEN & 0.418 & NGR/FTSE100 & 0.853 \\
NGR/SP500 & 0.183 & NGR/DAX & 0.729 \\
NGR/CAC40 & 0.986 & SA/KEN & 0.805 \\
SA/FTSE100 & 0.682 & SA/SP500 & 0.294 \\
SA/DAX & 0.119 & SA/CAC40 & 0.935 \\
KEN/FTSE100 & 0.100 & KEN/SP500 & 0.512 \\
KEN/DAX & 0.218 & KEN/CAC40 & 0.429 \\
FTSE100/SP500 & 0.904 & FTSE100/DAX & 0.895 \\
FTSE100/CAC40 & 0.502 & SP500/DAX & 0.742 \\
SP500/CAC40 & 0.314 & DAX/CAC40 & 0.244 \\
\hline
\end{tabular}

The parameter estimates and tail dependence coefficient for the best copula model from the twenty eight pairs of countries are given in Table 32. The K-plots are given in Figure 1.

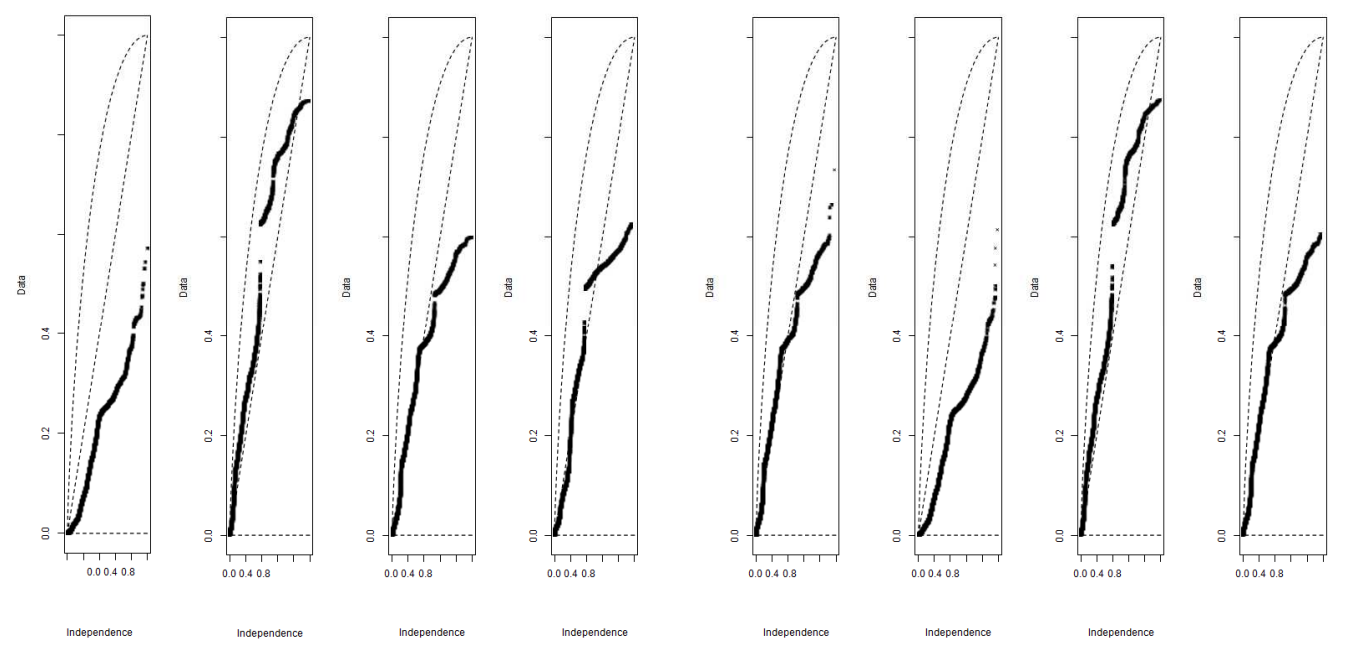




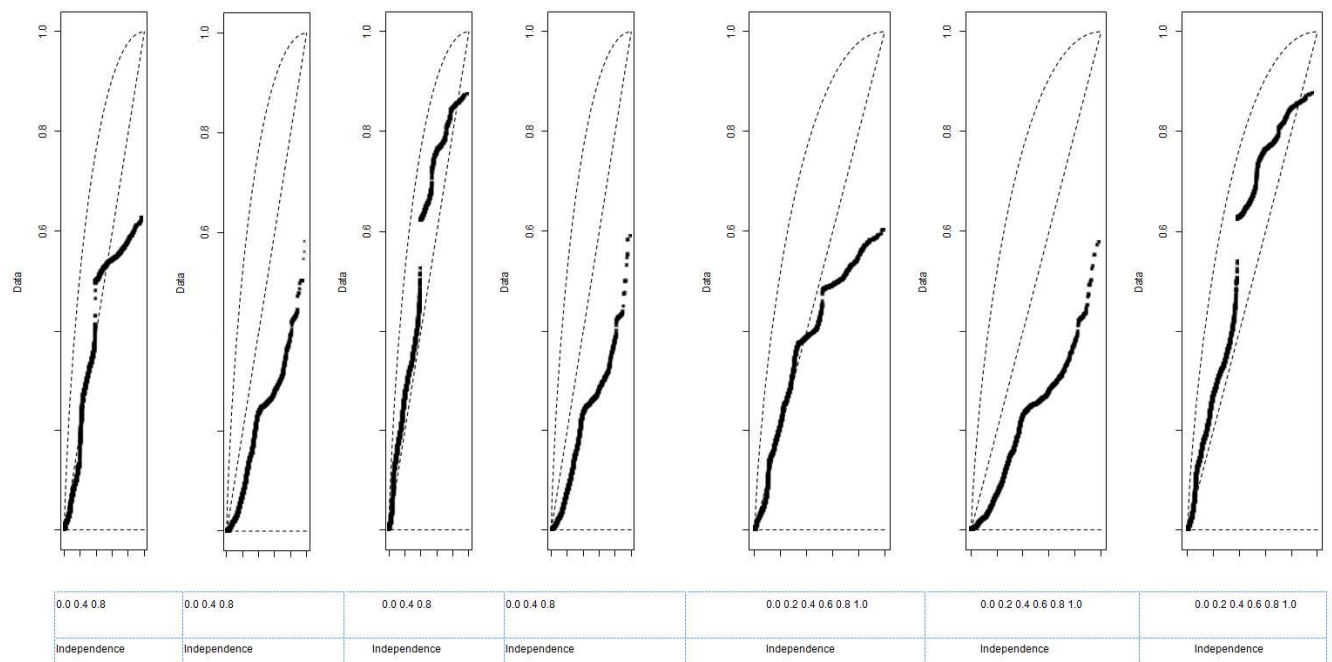

Figure 1. K-plots of daily log returns for the EGY v NGR, EGY v SA, EGY v KEN, EGY v FTSE, EGY v SP, NGR v SA, NGR v KEN, NGR v FTSE, (FIRST ROW) and NGR v SP, SA v KEN, SA v FTSE, FTSE v SP, SA v SP, KEN v FTSE, KEN v SP (SECOND ROW).

From the K-plots in Figure 1, evidence of possible tail dependence in African stock markets suspected. Note that K-plots are rank-based graphical tool for visualizing dependence (Genest and Boies [26]).

If we suppose $X$ and $Y$ to be random variables representing any set of pairs of daily $\log$ returns from these stock markets with marginal distribution functions $F$ and $G$. The coefficients of lower and upper tails dependence can be estimated by

$$
\lambda_{L}=\lim _{t \rightarrow 0^{+}} \operatorname{pr}\left[Y \leq G^{-1}(t) \mid X \leq F^{-1}(t)\right]
$$

and

$$
\lambda_{U}=\lim _{t \rightarrow 1^{-}} \operatorname{Pr}\left[Y>G^{-1}(t) \mid X>F^{-1}(t)\right],
$$

Respectively, if $\lambda_{L}=\lambda_{U}$, then $X$ and $Y$ are said to be symmetrically dependent in the tail, else they are asymmetric. It is important to note that joint extremes are more likely to occur with large values of $\lambda_{U}$ than for small values. 
Table 32. Parameter estimates and tail dependence coefficients for the best copula model.

\begin{tabular}{|c|c|c|c|}
\hline Country pairs & Copula & Parameter & Upper tail \\
\hline EGY/NGR & Gumbel & 1.2610 & 0.2673 \\
\hline EGY/SA & Gumbel & 1.1932 & 0.2124 \\
\hline EGY/KEN & Gumbel & 1.0224 & 0.0301 \\
\hline EGY/FTSE100 & Gumbel & 1.3396 & 0.3223 \\
\hline EGY/SP500 & Gumbel & 1.1672 & 0.1891 \\
\hline EGY/DAX & Gumbel & 1.0484 & 0.0630 \\
\hline EGY/CAC40 & Gumbel & 1.2193 & 0.2344 \\
\hline NGR/SA & Gumbel & 1.0857 & 0.1065 \\
\hline NGR/KEN & Gumbel & 1.2882 & 0.2872 \\
\hline NGR/FTSE100 & Gumbel & 1.0374 & 0.0494 \\
\hline NGR/SP500 & Gumbel & 1.3415 & 0.3235 \\
\hline NGR/DAX & Gumbel & 1.2679 & 0.2724 \\
\hline NGR/CAC40 & Gumbel & 1.0639 & 0.0816 \\
\hline SA/KEN & Gumbel & 1.4685 & 0.3967 \\
\hline SA/FTSE100 & Gumbel & 1.2555 & 0.2631 \\
\hline SA/SP500 & Gumbel & 1.0624 & 0.0798 \\
\hline SA/DAX & Gumbel & 1.4037 & 0.3615 \\
\hline SA/CAC40 & Gumbel & 1.0927 & 0.1142 \\
\hline KEN/FTSE100 & Gumbel & 1.3152 & 0.3061 \\
\hline KEN/SP500 & Gumbel & 1.1190 & 0.1422 \\
\hline KEN/DAX & Gumbel & 1.1639 & 0.1816 \\
\hline $\mathrm{KEN} / \mathrm{CAC} 40$ & Gumbel & 1.4632 & 0.3963 \\
\hline FTSE100/SP500 & Gumbel & 1.2655 & 0.2633 \\
\hline FTSE100/DAX & Gumbel & 1.0724 & 0.0799 \\
\hline FTSE100/CAC40 & Gumbel & 1.4137 & 0.3715 \\
\hline SP500/DAX & Gumbel & 1.1927 & 0.1242 \\
\hline SP500/CAC40 & Gumbel & 1.4152 & 0.4061 \\
\hline DAX/CAC40 & Gumbel & 1.1290 & 0.1432 \\
\hline
\end{tabular}

The value at risk and expected shortfall based on the best fitting copula model is computed. These two risk measures are the most popular and celebrated financial risk measures (Danielsson and de Vries [17]). Their popularity stems from its endorsement by the Basel committee as a standard for risk management. The results are given in Table 33. 
Table 33. Value at risk values based on the best performing models.

\begin{tabular}{ll}
\hline Country pairs & Value at risk \\
\hline EGY/NGR & 0.57125817 \\
EGY/SA & 0.73853789 \\
EGY/KEN & 0.99733551 \\
EGY/FTSE100 & 0.66329118 \\
EGY/SP500 & 0.21345670 \\
EGY/DAX & 0.80904588 \\
EGY/CAC40 & 0.89909111 \\
NGR/SA & 0.22234378 \\
NGR/KEN & 0.71946335 \\
NGR/FTSE100 & 0.25826023 \\
NGR/SP500 & 0.86496638 \\
NGR/DAX & 0.70241798 \\
NGR/CAC40 & 0.67201969 \\
SA/KEN & 0.70858934 \\
SA/FTSE100 & 0.01118940 \\
SA/SP500 & 0.06823602 \\
SA/DAX & 0.05963419 \\
SA/CAC40 & 0.80024248 \\
KEN/FTSE100 & 0.54397889 \\
KEN/SP500 & 0.29555464 \\
KEN/DAX & 0.56262578 \\
KEN/CAC40 & 0.40052473 \\
FTSE100/SP500 & 0.20129115 \\
FTSE100/DAX & 0.61733266 \\
FTSE100/CAC40 & 0.06094731 \\
SP500/DAX & 0.92853707 \\
SP500/CAC40 & 0.02947194 \\
DAX/CAC40 & 0.46954281 \\
\hline
\end{tabular}




\section{Conclusion}

The Gumbel copula was shown to give the best fit in terms of log-likelihood values and values of the Akaike information criterion, value of the Bayesian information criterion, value of the consistent Akaike information criterion, value of the corrected Akaike information criterion, and value of the Hannan-Quinn criterion and $p$-values of the information matrix equality of White [47]. Estimates of value at risk with probability $p$ for daily log returns are computed using the best fitting copula model. Based on these values at risk, it was clear that SA/FTSE have the least risks. In general, this finding has a number of implications for risk managers and potential investors. For instance, this shows that copula models should be used by policy-makers and financial practitioners to set margins, which is known to be sensitive to price movement in derivatives and stock markets.

\section{References}

[1] R. Aggarwal, C. Inclan and R. Leal, Volatility in emerging stock markets, Journal of Financial and Quantitative Analysis 34(1) (1999), 33-55.

https://doi.org/10.2307/2676245

[2] H. Akaike, A new look at the statistical model identification, IEEE Transactions on Automatic Control 19 (1974), 716-723. https://doi.org/10.1109/TAC.1974.1100705

[3] M. M. Ali, N. N. Mikhail and M. S. Haq, A class of bivariate distributions including the bivariate logistic, Journal of Multivariate Analysis 8 (1978), 405-412.

https://doi.org/10.1016/0047-259X(78)90063-5

[4] M. C. Ausin and H. F. Lopes, Time-varying joint distribution through copulas, Computational Statistics and Data Analysis 54 (2010), 2383-2399. https://doi.org/10.1016/j.csda.2009.03.008

[5] W. Bailey and R.M. Stulz, Benefits of international diversification: the case of Pacific Basin stock markets, J. Port. Mgt. 16 (1990), 57-61. https://doi.org/10.3905/jpm.1990.409287

[6] G. Bekaert and C. Harvey, Time-varying world market integration, Journal of Finance 50(2) (1995), 403-444. https://doi.org/10.1111/j.1540-6261.1995.tb04790.x

[7] G. Bekaert and C. Harvey, Emerging equity market volatility, Journal of Financial Economics 43(1) (1997), 29-77. https://doi.org/10.1016/S0304-405X(96)00889-6

[8] G. Bekaert, C.R. Harvey and R. L. Lumsdaine, Dating the integration of world equity markets, NBER Working Paper 6724, 1998. https://doi.org/10.3386/w6724 
[9] H. Bozdogan, Model selection and Akaike's Information Criterion (AIC): The general theory and its analytical extensions, Psychometrika 52 (1987), 345-370. https://doi.org/10.1007/BF02294361

[10] K. P. Burnham and D. R. Anderson, Multimodel inference: Understanding AIC and BIC in model selection, Sociological Methods and Research 33 (2004), 261-304. https://doi.org/10.1177/0049124104268644

[11] K.-L. Chang, The time-varying and asymmetric dependence between crude oil spot and futures markets: evidence from the mixture copula-based ARJI-GARCH model, Economic Modelling 29 (2012), 2298-2309.

https://doi.org/10.1016/j.econmod.2012.06.016

[12] Xiaohong Chen, Yanqin Fan and Andrew J. Patton, Simple tests for models of dependence between multiple financial time series, with applications to U.S. equity returns and exchange rates, London Economics Financial Markets Group Working Paper No. 483, 2004. https://doi.org/10.2139/ssrn.513024

[13] Queensley C. Chukwudum, Extreme value theory and copulas: reinsurance in the presence of dependent risks, Applied Mathematical Sciences 13(2) (2019), 67-86. https://doi.org/10.12988/ams.2019.811177

[14] S. Claessens and S. Gooptu, Portfolio investment in developing countries, The World Bank (1993), 1-8. https://doi.org/10.1596/0-8213-2747-X

[15] D. G. Clayton, A model for association in bivariate life tables and its application in epidemiological studies of familial tendency in chronic disease incidence, Biometrika 65 (1978), 141-151. https://doi.org/10.1093/biomet/65.1.141

[16] C. M. Cuadras and J. Augé, A continuous general multivariate distribution and its properties, Communication in Statistics - Theory and Methods 10(4) (1981), 339-353. https://doi.org/10.1080/03610928108828042

[17] J. Danielsson and C. G. de Vries, Value-at-risk and extreme returns, Annales d'Economie et de Statistique 60 (2000), 239-270. https://doi.org/10.2307/20076262

[18] Norou Diawara, Statistical pattern recognition using Gaussian copula, 2015. https://independent.academia.edu/noroudiawara

[19] Arjun B. Divecha, Jaime Drach and Dan Stefek, Emerging markets: a quantitative perspective, Journal of Portfolio Management 19(1) (1992) 41-50. https://doi.org/10.3905/jpm.1992.409433

[20] V. Durrleman, A. Nikeghbali and T. Roncalli, Which Copula is the Right One?, SSRN Electronic Journal, 2000. https://dx.doi.org/10.2139/ssrn.1032545 
[21] V. Errunza and K. Hogan, Macroeconomic determinants of European stock market volatility, European Financial Management 4(3) (1998), 361-377. https://doi.org/10.1111/1468-036X.00071

[22] V. Errunza, K. Hogan and M.-W. Hung, Can the gains from international diversification be achieved without trading abroad?, Journal of Finance 54(6) (1999), 2075-2107. https://doi.org/10.1111/0022-1082.00182

[23] Y. Fang, Asymptotic equivalence between cross-validations and Akaike information criteria in mixed-effects models, Journal of Data Science 9 (2011), 15-21. https://doi.org/10.6339/JDS.201101_09(1).0002

[24] Charles Fontaine, Jean-Pierre Daures and Paul Landais, On the censored costeffectiveness analysis using copula information, BMC Medical Research Methodology 17 (2017), Article No. 27. https://doi.org/10.1186/s12874-017-0305-9

[25] Edward W. Frees and E. A. Valdez, Understanding relationships using copulas, North American Actuarial Journal 2 (1998), 1-25. https://doi.org/10.1080/10920277.1998.10595667

[26] C. Genest and J.-C. Boies, Detecting dependence with Kendall plots, Am. Stat. 57 (2003), 275-284. https://doi.org/10.1198/0003130032431

[27] E. J. Gumbel, Bivariate exponential distributions, Journal of the American Statistical Association 55 (1960), 698-707. https://doi.org/10.1080/01621459.1960.10483368

[28] E. J. Hannan and B. G. Quinn, The determination of the order of an autoregression, Journal of the Royal Statistical Society 41 (1979), 190-195. https://doi.org/10.1111/j.2517-6161.1979.tb01072.x

[29] C. R. Harvey, Predictable risk and returns in emerging markets, The Review of Financial Studies 8(3) (1995), 773-816. https://doi.org/10.1093/rfs/8.3.773

[30] Jian Hu, Dependence structures in Chinese and U.S. financial markets: A time-varying conditional copula approach, SSRN Electronic Journal, 2008. https://doi.org/10.2139/ssrn.1296276

[31] W. Huang and A. Prokhorov, A goodness-of-fit test for copulas, Econometric Reviews 33(7) (2014), 751-771. https://doi.org/10.1080/07474938.2012.690692

[32] C. M. Hurvich and C.-L. Tsai, Regression and time series model selection in small samples, Biometrika 76 (1989), 297-307. https://doi.org/10.1093/biomet/76.2.297

[33] H. Joe, Parametric families of multivariate distributions with given margins, Journal of Multivariate Analysis 46 (1993), 262-282. https://doi.org/10.1006/jmva.1993.1061 
[34] Pranesh Kumar and Mohamed M. Shoukri, Copula based prediction models: an application to an aortic regurgitation study, BMC Medical Research Methodology 7 (2007), Article No. 21. https://doi.org/10.1186/1471-2288-7-21

[35] Donald Lien, Li Yang, Chunyang Zhou and Geul Lee, Co-movement between RMB and New Taiwan Dollars: Evidences from NDF markets, The North American Journal of Economics and Finance 28 (2014), 265-272. https://doi.org/10.1016/j.najef.2014.03.008

[36] A. W. Marshall and I. Olkin, A generalized bivariate exponential distribution, Journal of Applied Probability 4 (1967), 291-302. https://doi.org/10.2307/3212024

[37] A. Zeevi and R. Mashal, Beyond correlation: extreme co-movements between financial assets, SSRN Electronic Journal, 2002. https://doi.org/10.2139/ssrn.317122

[38] D. Morgenstern, Einfache beispiele zweidimensionaler verteilungen, Mitteilungsblatt für Mathematische Statistik 8 (1956), 234-235.

[39] R. B. Nelsen, An Introduction to Copulas, Springer-Verlag, New York, 1999. https://doi.org/10.1007/978-1-4757-3076-0

[40] A.J. Patton, Modelling time-varying exchange rate dependence using the conditional copula, UCSD Discussion Paper No. 01-09, 2001. https://doi.org/10.2139/ssrn.275591

[41] M. Sadegh, E. Ragno and A. Agha Kouchak, Multivariate copula analysis toolbox (MvCAT): describing dependence and underlying uncertainty using a Bayesian framework, Water Resour. Res. 53 (2017), 5166-5183.

https://doi.org/10.1002/2016WR020242

[42] G. E. Schwarz, Estimating the dimension of a model, Ann. Statist. 6 (1978), 461-464. https://doi.org/10.1214/aos/1176344136

[43] A. Sklar, Fonctions de répartition à $\mathrm{n}$ dimensions et leurs marges, Publications de l'Institut Statistique de l'Université de Paris 8 (1959), 229-231.

[44] Ugur Soytas and Ramazan Sari, The relationship between energy and production: evidence from Turkish manufacturing industry, Energy Economics 29(6) (2007), 11511165. https://doi.org/10.1016/j.eneco.2006.05.019

[45] R. Susmel and A. Thompson, Volatility, storage and convenience: evidence from natural gas markets, Journal of Futures Markets 17(1) (1997), 17-43. https://doi.org/10.1002/(SICI)1096-9934(199702)17:1\%3C17::AID-FUT2\%3E3.0.CO;2-J

[46] Beatriz Vaz de Melo Mendes, Computing conditional VaR using time-varying copulas, Brazilian Review of Finance 3 (2005), 251-265.

https://doi.org/10.12660/rbfin.v3n2.2005.1152 
[47] H. White, Regularity conditions for Cox's test of non-nested hypotheses, Journal of Econometrics 19(2-3) (1982), 301-318. https://doi.org/10.1016/0304-4076(82)90007-0

This is an open access article distributed under the terms of the Creative Commons Attribution License (http://creativecommons.org/licenses/by/4.0/), which permits unrestricted, use, distribution and reproduction in any medium, or format for any purpose, even commercially provided the work is properly cited. 